\title{
Who You Know Does Matter in Engineering Self Efficacy
}

\author{
Susan Amato-Henderson, Jessica Mariano, Pete Cattelino, \\ and Brian Hannon
}

\author{
Michigan Technological University
}

High performance in high school math and science are necessary prerequisites for success in science, technology, engineering or mathematics (STEM) majors in college. However, of the sub-group of students who excel in these areas in high school, very few choose to pursue a STEM degree in post-secondary education. Bandura's (1986) social cognitive theory suggests that a student's knowledge, skills, and previous accomplishments are not always the best predicators of subsequent attainments. Rather, their perception or beliefs about their capabilities can powerfully influence future behaviors or attainments.

An individual's perception of their ability to succeed in a given situation, known as self efficacy, influences their thoughts, feelings, motivation, and behavior (Bandura, 1994). Selfefficacy beliefs are task- and situation-specific, and are used in reference to personal goals (Pajares, 1997). The concept of self efficacy was first introduced by Bandura over 30 years ago (Bandura, 1977), and has since been the target of a wealth of research both within and outside of educational contexts.

According to Bandura (1994), four factors contribute to the development of self efficacy mastery experiences, vicarious experiences (i.e., modeling), social persuasion, and physiological states. Mastery experiences have the greatest impact on self-efficacy, with hands-on, authentic mastery experiences suggested to be more beneficial than other, non-purposive experiences (Pajares, 1997). Vicarious experiences include peer comparisons, social comparisons with others, and the impact of models. According to Pajares (1997), vicarious experiences have a smaller effect on self-efficacy than mastery experiences, but when an individual has limited personal experiences the impact may be greater. Schunk $(1981,1983,1987)$ found a significant impact of models in one's life on self-efficacy, influencing the course and direction of one's life. Social persuasion or verbal persuasions from others can also impact self-efficacy, although to a lesser degree than both mastery experiences and vicarious experiences (Pajares, 1997). Interestingly, Bandura (1986) found it was easier to weaken self-efficacy beliefs through negative appraisals than it was to strength them through positive appraisals. Finally, the impact of physiological states on self-efficacy is akin to perceiving the anxieties and fears about capabilities as indicators of a lack of ability to succeed - higher emotional arousal in this situation will lead to lower confidence or self-efficacy (Bandura, 1997).

Research within the educational arena has established a relationship between self efficacy and college major and career choice, particularly in science and mathematics (see Lent \& Hackett, 1987, for a review). For example, college students' mathematics self-efficacy is more predictive of both their interest in math and their enrollment in math courses than their prior math achievement, with male undergraduates reporting higher mathematics self-efficacy than 
Knowing an Engineer and Engineering Self-Efficacy

females (Hackett, 1985; Hackett \& Betz, 1989; Lent, Lopez, \& Bieschke, 1991, 1993; Pajares \& Miller, 1994, 1995). Numerous studies examining the role of self efficacy in students' pursuit of engineering careers have generally found a positive correlation between self-efficacy and academic achievement in engineering disciplines (AWE, 2005). For example, it has been found that one's self-efficacy beliefs influence on effort, persistence, and perseverance in goal attainment (Bandura \& Schunk, 1981; Bouffard-Bouchard, 1990; Schunk \& Hanson, 1985). Similar findings reveal that high self-efficacy beliefs influence the academic persistence necessary to maintain high academic achievement amongst college students enrolled in science and engineering courses (Lent, Brown, \& Larkin, 1984, 1986).

Previous research has clearly made the case that the construct of engineering self efficacy can be an important contributor to success in STEM career education by influencing the choice to pursue STEM careers and the persistence with which it is pursued. However, this research is largely based upon post-secondary school aged samples. While a large amount of research exists examining the role of occupational efficacy in adults or young adults, comparatively little research has been conducted examining the development and importance of self-efficacy beliefs in adolescents’ career choice (Bandura, Barbaranelli, Caprara \& Pastorelli, 2001).

The current study, examining engineering self-efficacy in middle and high school students, was part of a larger study examining the effects of the Youth Engineering and Science Expo (YES! Expo). The YES! Expo is a tradeshow style event held at Ford Field, in Detroit, designed to stimulate engineering and science career interests in middle and high school students. Exhibitors from numerous universities and corporations provide hands-on discovery of STEM careers during the show for approximately 15,000 students in attendance. For example, students were able to contribute toward the building of a Habitat for Humanity home (sponsored by Pulte Homes, Inc.), tinker with robotics, view hybrid cars, "visit” outer space (in the NASA exhibit), use surveyor equipment, create rust, and view and manipulate their physiological measurements (Heart rate, blood pressure, skin conductance). Event exhibitors included Cranbrook Institute of Science, The New Detroit Science Center, FIRST Robotics, Girl Scouts of Metro Detroit, Habitat for Humanity Detroit, the Henry Ford Museum, NASA and the U. S. Department of Education.

One purpose of this research was to examine the impact of attendance at the YES! Expo on adolescents' engineering self efficacy through pre and post-event surveys. In addition, responses to the question "Do you know someone who is an engineer?" were treated as a grouping variable for later analyses to determine the impact of knowing an engineer on engineering self-efficacy. Given the previous research demonstrating an impact of vicarious experiences and social persuasion on self-efficacy, it was hypothesized that students who reported knowing an engineer would report higher engineering self-efficacy.

\section{Method}

Participants

A convenience sample of YES! Expo attendees who completed both the pre-attendance survey and post-attendance survey served as participants for this project $(\mathrm{N}=204)$, approximately half of which were middle school students $(n=99$, accounting for $48.5 \%$ of the sample). Over $60 \%$ of the respondents were female $(n=124)$. A majority of respondents 
Knowing an Engineer and Engineering Self-Efficacy

reported their ethnicity as Black/African-American ( $=97$, or $47.8 \%$ of sample) or White/Caucasian ( $\mathrm{n}=86$, or $42.4 \%$ of sample).

\section{Materials}

A survey was designed to measure demographics, engineering self efficacy, course enrollment and extra-curricular behavior, and expectations and perceptions of the YES! Expo. Of importance to this research was the measure of engineering self efficacy. A modified version of the Longitudinal Assessment of Engineering Self Efficacy (LAESE) instrument was used (http://www.engr.psu.edu/awe/). The LAESE was designed and validated for use with undergraduate women studying engineering by the NSF-funded Assessing Women in Engineering Project, or AWE (NSF HRD 0120642). Items in the original LAESE address numerous aspects of self-efficacy including efficacy in barrier situations, expected outcomes, workload, and ability to succeed in engineering education.

The modified version of the LAESE used in this research was designed to be applicable to both male and female middle and high school students. Thus, items from the original LAESE regarding college courses, academic advisors, and other items relevant only to college students were not utilized. The modified instrument contained 15 agree/disagree statements on which participants rated their level of agreement on a 7-point Likert-type scale ( 0 = strongly disagree; 6 = strongly agree). Example statements on the modified self-efficacy instrument were: I can complete any Engineering degree at college; I can complete the physics requirements for most Engineering majors; and A degree in Engineering will allow me to get a job where I can use my talents and creativity.

\section{Procedure}

Approximately 30 educators who had signed up to attend the YES! Expo and also lived within a 20-mile radius of the event location were invited to participate by conducting the preand post-event surveys in their classrooms. Twenty-four educators agreed to participate. Preevent surveys were completed $1-2$ days prior to attending the YES! Expo and post-event surveys were completed within 2 weeks of attendance. Students who completed both the pre and post event surveys were included in the data analysis for this project.

\section{Results}

The mean response across the15-item engineering self efficacy instrument was calculated for each participant on both the pre- and post-event assessment. Thus, a pre-event and postevent engineering self-efficacy score resulted for each participant, with values ranging from 0 to 6. Higher values reflected higher levels of engineering self-efficacy beliefs.

To examine the impact of attendance at the YES! Expo on engineering self-efficacy, a paired-samples t-test was conducted on the pre- and post-event engineering self-efficacy scores. No significant differences existed in the scores [ $\mathrm{t}(203)=.764, \mathrm{p}=.446$ ], with a mean engineering self-efficacy score on the pre-event assessment of $4.36(\mathrm{SD}=.696, \mathrm{n}=204)$ and a mean engineering self-efficacy on the post event assessment of $4.33(\mathrm{SD}=.822, \mathrm{n}=204)$. A significant positive correlation existed between the pre- and post-event engineering self-efficacy scores $(r=.609, \mathrm{p}<.000)$. 
Knowing an Engineer and Engineering Self-Efficacy

The roles of gender, school level (middle vs. high school) and knowing an engineer on the pre- and post-event engineering self efficacy scores were examined using a 2 x 2 x 2 multivariate ANOVA. No significant interactions existed between gender, school level and knowing an engineer. Results of the analyses examining main effects of each variable are discussed below.

No differences in gender existed $[\mathrm{F}(2,192)=1.014, \mathrm{p}=.365]$, with males and females having similar engineering self-efficacy scores. While main effects of school level existed on the multivariate analysis $[\mathrm{F}(2,192)=4.95, \mathrm{p}=.008]$, follow-up between-subject tests revealed no significant differences between middle school and high school participants on either the pre- or post-event engineering self efficacy measures.

To determine the impact of knowing an engineer on engineering self-efficacy, responses to the question "Do you know someone who is an engineer?" were treated as a grouping variable (129 students reported knowing an engineer, 71 students reported not knowing an engineer). A significant main effect of knowing an engineer existed $[F(2,192)=4.74, p=.01$. Students who reported knowing an engineer had higher self efficacy scores, $4.49(S D=.658)$ and $4.44(S D=$ .765) on the pre and post event assessments respectively. Participants who reported not knowing an engineer had significantly lower engineering self-efficacy scores (pre-event $m=4.17, S D=$ .679 ; post event $m=4.12, S D=.896$ ). See Figure 1 for a comparison of engineering selfefficacy mean scores as a function of knowing an engineer.

Figure 1. Mean Engineering Self Efficacy as a Function of Knowing an Engineer

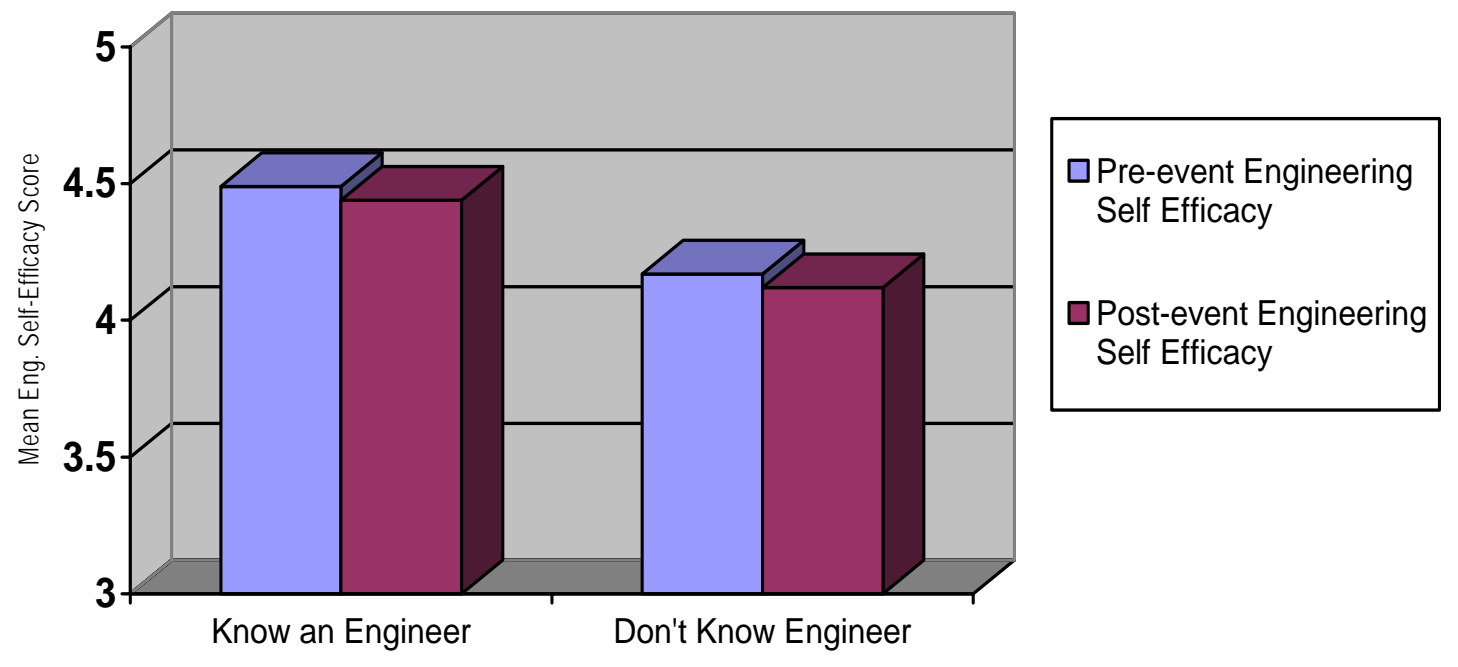

\section{Discussion}

Attendance at the YES! Expo did not influence engineering self-efficacy as assessed in this project. A variety of explanations could exist for this finding, the most parsimonious being that attendance at the 4-hour trade-show style event did not impact students' beliefs in their ability to succeed in engineering majors or careers. In terms of the four factors impacting selfefficacy beliefs, this explanation is logical. The event likely did not provide purposeful mastery experiences for students. Instead, the event could be better viewed as one in which social persuasions are the most likely influence on attendees' engineering self-efficacy beliefs. Given 
Knowing an Engineer and Engineering Self-Efficacy

previous findings that social persuasions have a smaller impact on self-efficacy than either mastery or vicarious experiences (Pajares, 1997), and may even be more effective at weakening self-efficacy through negative appraisals, these findings are not surprising. Other variables designed to measure the impact of YES! Expo on students career interests, knowledge, etc. found a positive impact of the event (variables were included as part of the larger project and not discussed in this paper).

The hypothesis that students who knew an engineer would have higher engineering selfefficacy was supported. Knowing an engineer can provide a student with a role-model, in addition to more knowledge about what engineers actually do. In line with previous research revealing the impact of vicarious experiences through modeling on self-efficacy, it appears as though engineering self-efficacy may also be prone to positive benefits of role-models in adolescence. Much research exists touting the benefits and importance of engineering student mentoring at the university level, but the funnel into STEM careers begins much sooner than the freshman year. The results of this study suggest future research should examine the role of mentors during adolescence on students' career interests and choices. Is a mentoring relationship necessary or is simply the knowledge of what real-world engineers do important? Does the relationship need to be long-term? How might engineers best serve as role-models for adolescents? These and other questions demand attention to widen the funnel into STEM careers.

\section{References}

Bandura. A. (1977). Self-efficacy: Toward a unifying theory of behavioral change. Psychological Review, 84, 191-215.

Bandura, A. (1986). Social foundations of thought and action: A social cognitive theory. Englewood Cliffs, NJ: Prentice Hall.

Bandura, A. (1997). Self-efficacy: The exercise of control. New York: Freeman.

Bandura, A., Barbaranelli, C., Caprara, G.V., Pastorelli, C. (2001). Self-efficacy beliefs as shapers of children's aspirations and career trajectories. Child Development, 72 (1), 187-206.

Bandura, A., \& Schunk, D. H. (1981). Cultivating competence, self-efficacy, and intrinsic interest through proximal self-motivation. Journal of Personality and Social Psychology, 41, 586-598

Bouffard-Bouchard, T. (1990). Influence of self-efficacy on performance in a cognitive task. Journal of Social Psychology, 130, 353-363

Hackett, G. (1985). The role of mathematics self-efficacy in the choice of math-related majors of college women and men: A path analysis. Journal of Counseling Psychology, 32, 47-56 
Knowing an Engineer and Engineering Self-Efficacy

Hackett, G., \& Betz, N. E. (1989). An exploration of the mathematics self-efficacy/mathematics performance correspondence. Journal for Research in Mathematics Education, 20, 261-273.

Lent, R. W., Brown, S. D., \& Larkin, K. C. (1984). Relation of self-efficacy expectations to academic achievement and persistence. Journal of Counseling Psychology, 31, 356-362.

Lent, R. W., Brown, S. D., \& Larkin, K. C. (1986). Self-efficacy in the prediction of academic performance and perceived career options. Journal of Counseling Psychology, 33, 265-269.

Lent, R. W., Lopez, F. G., \& Bieschke, K. J. (1991). Mathematics self-efficacy: Sources and relation to science-based career choice. Journal of Counseling Psychology, 38, 424-430.

Lent, R. W., Lopez, F. G., \& Bieschke, K. J. (1993). Predicting mathematics-related choice and success behaviors: Test of an expanded social cognitive model. Journal of Vocational Behavior, 42, 223-236.

Pajares, F. (1997). Current directions in self-efficacy research. In M. Maehr \& P. R. Pintrich (Eds.). Advances in motivation and achievement, Volume 10, (pp. 1-49). Greenwich, CT: JAI Press.

Pajares, F., \& Miller, M. D. (1994). The role of self-efficacy and self-concept beliefs in mathematical problem-solving: A path analysis. Journal of Educational Psychology, 86, 193203.

Pajares, F., \& Miller, M. D. (1995). Mathematics self-efficacy and mathematics outcomes: The need for specificity of assessment. Journal of Counseling Psychology, 42, 190-198.

Schunk, D. H. (1981). Modeling and attributional effects on children's achievement: A selfefficacy analysis. Journal of Educational Psychology, 73, 93-105.

Schunk, D. H. (1983). Developing children's self-efficacy and skills: The roles of social comparative information and goal setting. Contemporary Educational Psychology, 8, 76-86.

Schunk, D. H. (1987). Peer models and children's behavioral change. Review of Educational Research, 57, 149-174.

Schunk, D. H., \& Hanson, A. R. (1985). Peer models: Influence on children's self-efficacy and achievement. Journal of Educational Psychology, 77, 313-322.

\section{Biographical Information}

SUSAN AMATO-HENDERSON, Associate Professor of Psychology at Michigan Technological University (Ph.D. in Experimental Psychology, University of North Dakota), conducts research in psychology and the law, service learning and educational outcomes assessment. She was the lead investigator in the YES! Expo Assessment. 


\section{Knowing an Engineer and Engineering Self-Efficacy}

JESSICA MARIANO is pursuing a Bachelors of Science degree in Psychology at Michigan Technological University. She is an undergraduate research assistant, working with Dr. Amato and YES! Expo coordinators to conduct this research.

PETER J. CATTELINO earned a BS degree from Michigan Technological University and is the Director of YES! Expo. He is responsible for all aspects of the event including sponsor and school/student recruitment, budgeting, logistics, and communications and promotion.

BRIAN G. HANNON earned a BA in Liberal Arts from Michigan Technological University. He is the lead member of Michigan Tech's Corporate Development Team responsible for recruiting sponsors and partners for YES! Expo. 